\title{
Risk Stratification and Clinical Profile of Newly Detected Type 2 Diabetes Mellitus in Rural India
}

\author{
Srikanth Evuru \\ Associate Professor of General medicine, NRI Medical College, Chinakakani, Guntur district, AP, India
}

\begin{abstract}
Aim of the study is to risk stratify and assess the clinical profile of newly detected type 2 DM in rural India. Introduction: The determinants of the epidemic are the rapid epidemiological transition associated with changes in dietary patterns and decreased physical activity. A wide range of factors are contributing, amongst which diet and lifestyles are biggest culprit in the case of DM in addition to the genetic factors. Two important determinants are genetic background and obesity. Other major risk factors are physical inactivity and insulin resistance. Rural areas which have undergone socio-economic transition in the last two decades show nearly a threefold increase in the prevalence of diabetes. Results: Among 50 patients attending the study, the major age group is between 40 and 50. The mean age of onset of diabetes is 49.2. Male to female ratio is 3:2Most patients are illiterate and have farming as occupation and majority are Hindus. 23 patients have first degree relatives with diabetes and 4 patients have diabetes extending up to 2 generations. Even though the study was done in rural population, childhood obesity is present in $52 \%$ of patients. Smoking and alcoholism is present in $20 \%$ and $22 \%$ respectively. $64 \%$ have moderate to sedentary physical activity. $74 \%$ are obese. $83 \%$ of male and $90 \%$ of females have abdominal obesity.60\% have normal blood pressure, $20 \%$ have pre HTN and $10 \%$ have stage1 and 10\% have stage 2 HTN. Conclusion: Rural India which is well known for hard working and fit personalities is slowly being replaced by childhood obesity, less physical activity, adult obesity, increased waist circumference and increased incidence of metabolic diseases like diabetes and coronary artery disease.
\end{abstract}

Keywords: type 2 diabetes, obesity in diabetes, rural India, risk factors of diabetes, clinical profile of diabetes

\section{Introduction}

Diabetes mellitus is defined as a metabolic abnormality characterized by hyperglycemia and disturbances of carbohydrate, fat and protein metabolism that are associated with absolute or relative deficiency in insulin secretion and or insulin action [1]. According to the recent global estimates of the WHO, there will be 300 million people with diabetes by the year 2025 [2]

The determinants of the epidemic are the rapid epidemiological transition associated with changes in dietary patterns and decreased physical activity. A wide range of factors are contributing, amongst which diet and lifestyles are biggest culprit in the case of DM in addition to the genetic factors. Two important determinants are genetic background and obesity.

Other major risk factors are physical inactivity and insulin resistance. Rural areas which have undergone socioeconomic transition in the last two decades show nearly a threefold increase in the prevalence of diabetes.

This study was initiated with the objective to estimate the risk factors of people newly diagnosed to have type 2 diabetes mellitus.

\section{Methodology}

This is a cross-sectional study, conducted among patients of rural background visiting NRIGH a hospital of NRI medical college from December 2015 to June 2016 with symptoms suggestive of diabetes mellitus. Diagnosis of diabetes was made by oral glucose tolerance test and $\mathrm{HbA} 1 \mathrm{C}$.

Risk stratification was done for all people diagnosed as diabetes. Factors like socio-demographic details, family history of diabetes, history of childhood obesity, symptoms, physical activity, smoking, alcoholism were recorded from the patient. Subsequently height, weight, abdominal circumference, waist hip ratio and blood pressure were measured.

\section{Statistical Analysis}

The data was entered in MS excel 2007 and analyzed using descriptive statistical measures like mean and percentages.

\section{Results}

Among 50 patients attending the study, the major age group is between 40 and 50 . The mean age of onset of diabetes is 49.2 .

Male to female ratio is $3: 2$

Most patients are illiterate and have farming as occupation and majority are Hindus. 23 [46\%] patients have first degree relatives with diabetes and 4 patients have diabetes extending up to 2 generations.

Even though the study was done in rural population, childhood obesity is present in $52 \%$ of patients. Smoking and alcoholism is present in $20 \%$ and $22 \%$ respectively. $64 \%$ have moderate to sedentary physical activity. $74 \%$ are obese. $83 \%$ of male and $90 \%$ of females have abdominal obesity. $60 \%$ have normal blood pressure, $20 \%$ have pre HTN and $10 \%$ have stage 1 and $10 \%$ have stage 2 HTN. 


\section{International Journal of Science and Research (IJSR) ISSN (Online): 2319-7064}

Index Copernicus Value (2013): 6.14 | Impact Factor (2015): 6.391

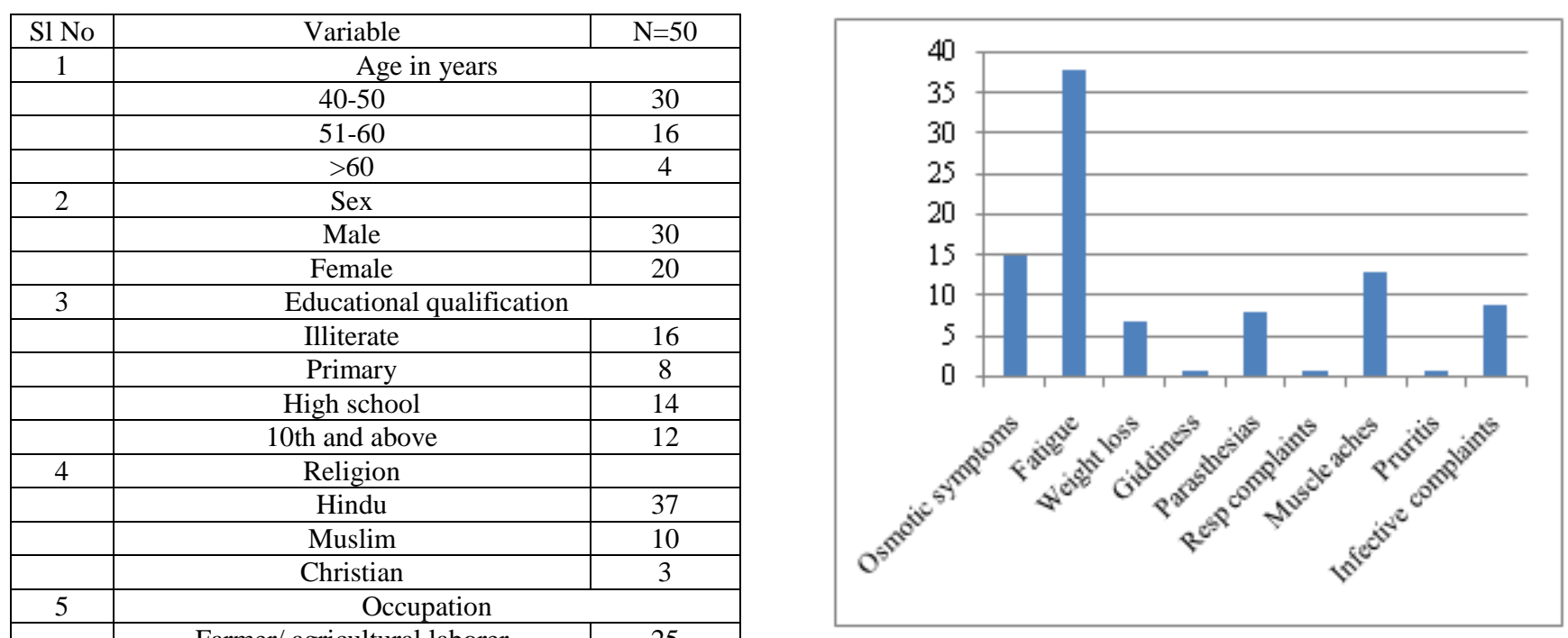

\begin{tabular}{|c|c|c|c|}
\hline & Farmer/ agricultural laborer & 25 & \multirow{5}{*}{$\begin{array}{l}\text { OGTT was done in all patients with symptoms suggestive of } \\
\text { diabetes. Fasting blood sugar ranged from } 110 \mathrm{mg} / \mathrm{dl} \text { to } 260 \\
\mathrm{mg} / \mathrm{dl} \text { with a mean FBS of } 158.6 \mathrm{mg} / \mathrm{dl} .2^{\text {nd }} \mathrm{hr} \text { blood sugars } \\
\text { ranged from } 200 \mathrm{mg} / \mathrm{dl} \text { to } 400 \mathrm{mg} / \mathrm{dl} \text { with a mean } 2^{\text {nd }} \mathrm{hr} \text { sugar } \\
\text { of } 262.4 \mathrm{mg} / \mathrm{dl} \text {. }\end{array}$} \\
\hline & Housewife & 17 & \\
\hline & Others & 8 & \\
\hline 6 & \multicolumn{2}{|c|}{ Family history of diabetes } & \\
\hline & Present & & \\
\hline
\end{tabular}

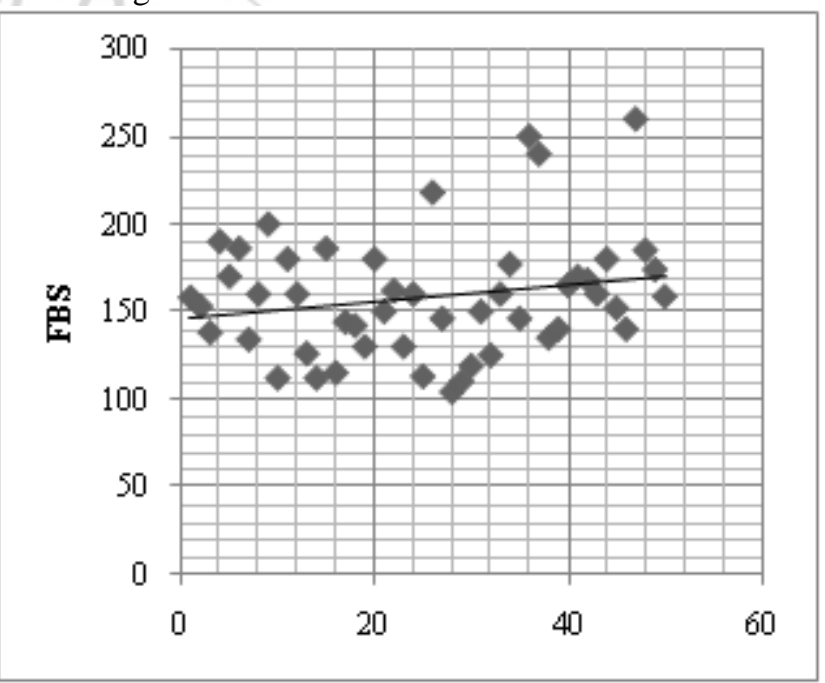

\begin{tabular}{|l|c|c|}
\hline 7 & History of childhood obesity & 26 \\
\hline & Present & 24 \\
\hline & Absent & 18 \\
\hline 8 & Physical activity & 20 \\
\hline & Active & 12 \\
\hline & Moderate & \\
\hline & Sedentary & 10 \\
\hline 9 & Smoking & 40 \\
\hline & Present & 11 \\
\hline 10 & Absent & 39 \\
\hline & Alcoholism & \\
\hline & Present & 3 \\
\hline 11 & Absent & 10 \\
\hline & BMI & 19 \\
\hline & $18.5-22.9$ & 14 \\
\hline
\end{tabular}

\begin{tabular}{|c|c|c|}
\hline & $>35$ & 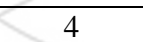 \\
\hline \multirow[t]{7}{*}{12} & Waist circumference & $x^{2}$ \\
\hline & Male & 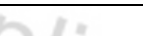 \\
\hline & 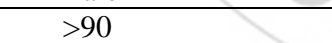 & 25 \\
\hline & $<90$ & 5 \\
\hline & Female & 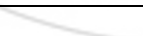 \\
\hline & $>80$ & 18 \\
\hline & $<80$ & 2 \\
\hline \multirow[t]{9}{*}{13} & Waist hip ratio & \\
\hline & Male & \\
\hline & $<0.95$ & 7 \\
\hline & $0.96-1.0$ & 11 \\
\hline & $>1$ & 12 \\
\hline & Female & \\
\hline & $<0.8$ & 2 \\
\hline & $0.81-0.85$ & 4 \\
\hline & $>0.85$ & 14 \\
\hline \multirow[t]{5}{*}{14} & Blood pressure & \\
\hline & Normal & 30 \\
\hline & Pre HTN & 10 \\
\hline & Stage1 HTN & 5 \\
\hline & Stage2 HTN & 5 \\
\hline
\end{tabular}

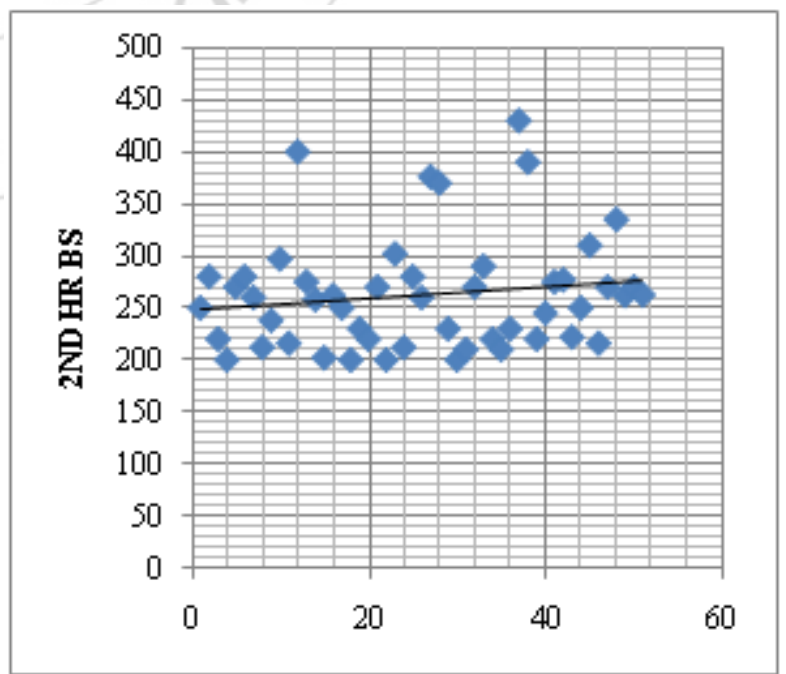

Gylcosylated hemoglobin is done in all patients to diagnose diabetes and the diagnostic value is more than or equal to 7 The value ranged from 7 to 10.8 and the mean value is 8 .

Fatigue is the commonest presenting complaint followed by osmotic symptoms like polyurea, polydypsia.

Volume 5 Issue 5, May 2016 www.ijsr.net 


\section{International Journal of Science and Research (IJSR) \\ ISSN (Online): 2319-7064}

Index Copernicus Value (2013): 6.14 | Impact Factor (2015): 6.391

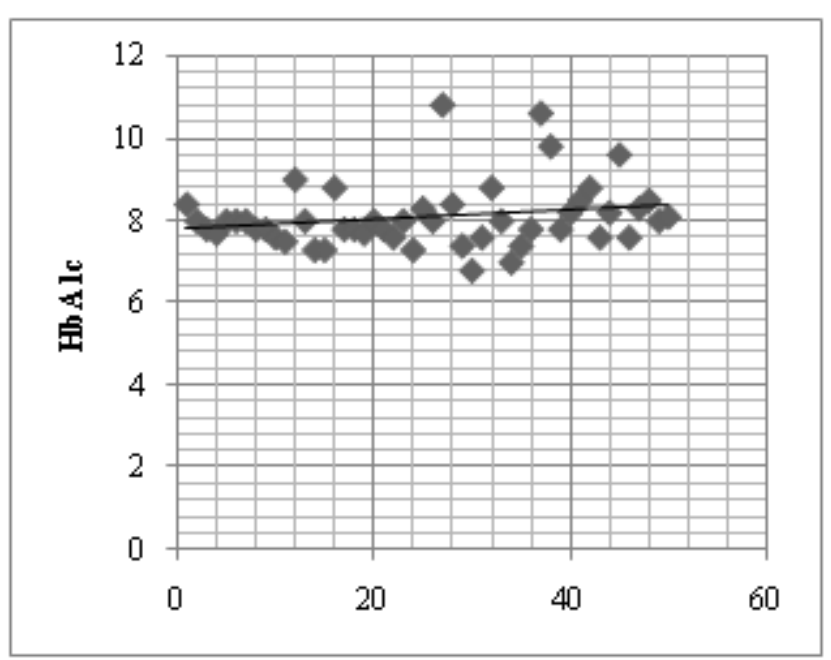

\section{Discussion}

India, with 1.2 billion people is the second most populous country in the world and is currently experiencing rapid epidemiological transition. Under nutrition due to poverty which dominated in the past, is being rapidly replaced by obesity associated with affluence6. Industrialization and urbanization also contribute to increased prevalence of obesity. Studies from different parts of India have provided evidence of the rising prevalence of obesity. This study was done in rural population and risk factors leading to diabetes are studied. Rural India which is well known for hard working and fit personalities is slowly being replaced by childhood obesity, less physical activity, adult obesity, increased waist circumference and increased incidence of metabolic diseases like diabetes and coronary artery disease.

\section{References}

[1] Report on the cologne digital Sanskrit lexicon project. Assessed on 10 February 2012.

[2] King Hubert RE. Herman WH et al. global burden of diabetes. 1995-2025. Diabetes care 1998 21:1441-31

[3] Guptha et al. prevalence of diabetes in India. Symposia on diabetes in Asia 6-7 February 1981.

[4] Mc Keigue PM et al. Relation of central obesity and insulin resistance with high diabetes prevalence and cardio vascular risk in south Asians. Lancet1991; 337:382-6.

[5] Gress TW et al. hypertension and anti hypertensive therapy as arisk factor for diabetesmellits. New ingland journal of medicine 2000;342:905-12.

\section{Author Profile}

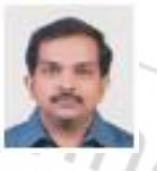

Dr. Srikanth Evuru recievied MBBS degree from Rangaraya Medical College, Kakinada, AP,INDIA, M.D post graduation from rajah muttiah medical college, Chidambaram, TN, INDIA, he worked as an assistant professor and subsequently working as associate professor at NRI medical college, chinakakani, AP, INDIA

DM was highest in people who were illiterate and with primary education. This shows role of education in prevalence of diabetes.

DM was more prevalent in housewives and men who are moderate to sedentary men with farming profession.

DM was higher in the people who had a positive family history of diabetes as compared to those who did not the above is consistent with results Guptha et al [3].

DM was prevalent in obese individuals. Similar results were reported by Mc Keigue PM 1991 [4].

Among diabetics $20 \%$ are hypertensive. Similar results were reported by Gress et al [5].

\section{Conclusion}

Rural India which is well known for hard working and fit personalities is slowly being replaced by childhood obesity, less physical activity, adult obesity, increased waist circumference and increased incidence of metabolic diseases like diabetes and coronary artery disease. 